\title{
RAPID ANALYSIS OF FINASTERIDE IN BULK AND FORMULATIONS BY RP-HPLC-PDA METHOD
}

\author{
SINDHURA MANNE, RAGHAVI KAKARLA, PRASHANTHI RAAVI, BUCHI N. NALLURI*
}

K.V.S.R Siddhartha College of Pharmaceutical Sciences, Vijayawada-520010, AP, INDIA

(Received: February 6, 2012 - Accepted: September 4, 2012)

\begin{abstract}
A simple, precise, rapid and accurate LC-MS compatible RP-HPLC-PDA method has been developed and validated for the estimation of Finasteride (FIN) in bulk and tablet formulations. The chromatographic separation was achieved on Phenomenex $\mathrm{C}_{18}$ column $(150 \mathrm{~mm} \times 4.6 \mathrm{~mm}, 5.0 \mu$ particle size $)$ using the mobile phase comprising $0.02 \%$ formic acid (in water): methanol in the ratio of $20: 80(\mathrm{v} / \mathrm{v})$ at a flow rate of $1 \mathrm{~mL} / \mathrm{min}$ and FIN was eluted at 3.4 min. Quantification and linearity were achieved at $220 \mathrm{~nm}$ over the concentration range of $5-50 \mu \mathrm{g} / \mathrm{mL}$ and the percentage mean of assay was found to be 100.29 . The method was validated for specificity, linearity, accuracy, precision, LOD, LOQ, stability and robustness as per the ICH guidelines and is suitable to be employed in Quality Control.
\end{abstract}

Keywords: Rapid, Finasteride, HPLC, validation, LC-MS compatible, Phenomenex $\mathrm{C}_{18}$ column, $220 \mathrm{~nm}$.

\section{INTRODUCTION}

Finasteride, a synthetic 4-azasteroid compound, is a specific inhibitor of steroid Type II $5 \alpha$-reductase, an intracellular enzyme that converts the androgen testosterone into $5 \alpha$-dihydrotestosterone (DHT) $[1,4]$. Conversion of testosterone to DHT by 5 -alpha reductase is essential for prostatic hyperplasia. Chemically, FIN is $N$-(1, 1-dimethylethyl)--3-oxo-4-aza-5a-androst-1-ene$17 b$-carboxamide $[2,3]$. The empirical formula of $\mathrm{FIN}$ is $\mathrm{C}_{23} \mathrm{H}_{36} \mathrm{~N}_{2} \mathrm{O}_{2}$ and its molecular weight is $372.55[5,6]$.

Methods reported earlier include UV Spectrophotometry, LC-MS, and some HPLC methods most of which were meant for bio analysis [7-14]. In one study by Hulya et al [10] reported a retention time of $30 \mathrm{~min}$ for FIN with LOD $31.25 \mu \mathrm{g} / \mathrm{mL}$ and LOQ $93.75 \mu \mathrm{g} / \mathrm{mL}$. In another study by Basavaiah and Somashekar [11] the retention time of $6 \mathrm{~min}$ was reported and the method was not sensitive. In most of published HPLC methods the retention times for FIN are longer and had low sensitivity. Hence, the present investigation was aimed at developing a validated, rapid and sensitive RP-HPLC analytical method for the estimation of FIN in bulk and pharmaceutical dosage forms.

\section{MATERIALS AND METHODS}

FIN was generous gifts from Dr. Reddy's Labs (Hyderabad, India). Tablets were purchased from local market, the labelled amount was $5 \mathrm{mg}$ FIN each (FINAST, B.NO: A000151). Methanol, water and formic acid and other chemicals and reagents were of HPLC grade.

\section{HPLC Instrument}

A Shimadzu Prominence HPLC system provided with DGU-20A3 degasser, LC-20AD binary pumps, SIL-20AHT auto sampler, and SPD-M20A PDA detector was used. Data acquisition was carried out using LC solutions software. The chromatographic analysis was performed on $\mathrm{C}_{18}$ Phenomenex $(150 \times 4.6 \mathrm{~mm}, 5 \mu, 100 \AA)$ column.

\section{Chromatographic conditions}

The mobile phase consisted of $0.02 \%$ formic acid (in water): methanol in the ratio of $20: 80(\mathrm{v} / \mathrm{v})$, which was previously filtered through $0.45 \mu \mathrm{m}$ membrane filter. The flow rate was optimized to $1 \mathrm{~mL} / \mathrm{min}$, which yielded a column backpressure of 95-99 $\mathrm{kgf}$. The run time was set to $7 \mathrm{~min}$ and the detection was carried out at $220 \mathrm{~nm}$. The volume of injection was $20 \mu \mathrm{L}$ and the column was equilibrated for at least $30 \mathrm{~min}$ with the mobile phase prior to the starting of the samples sequence for base line checking.

Preparation of the Standard solution

A stock solution was prepared by dissolving $10 \mathrm{mg}$ of standard in a $10 \mathrm{~mL}$ volumetric flask containing about $6 \mathrm{~mL}$ of methanol (HPLC grade). The solution was sonicated and the volume was made up to the mark with methanol to obtain a stock solution of $1 \mathrm{mg} / \mathrm{mL}$. Daily, the working standard solutions were prepared by suitably diluting it with $0.02 \%$ formic acid (diluent) to get the required concentrations.

\section{Preparation of the Sample solution}

10 tablets were weighed and finely powdered. The blend equivalent to 10 $\mathrm{mg}$ of FIN was transferred to a $10 \mathrm{~mL}$ volumetric flask containing about $6 \mathrm{~mL}$ of methanol, sonicated and made up to the mark with the same. The mixture was centrifuged and filtered through $0.22 \mu \mathrm{m}$ nylon membrane filter to obtain a stock solution of $1 \mathrm{mg} / \mathrm{mL}$. It was further diluted with diluent to get the required concentration.

\section{Method Validation}

Linearity

The linearity of FIN responses in the concentration range of 5 to $50 \mu \mathrm{g} / \mathrm{mL}$ was determined.

Precision

Precision was measured in terms of repeatability of application and measurement. Study was carried out by injecting six replicates of the standard and sample at a concentration of $30 \mu \mathrm{g} / \mathrm{mL}$. The data was shown in Figure - 2 .

Specificity

Specificity studies were carried for both pure drug and drug product by comparing the $3 \mathrm{D}$ plots with blank and placebo. Peak purity tests were also carried out to show that the analyte chromatographic peak is not attributable to more than one component as the impurities are not available by purity index data. The data was shown in Figures-3 \& 4.

Accuracy

Accuracy (Recovery) of the method was determined by spiking 80, 100 and $120 \%$ of FIN working standard at a concentration of $30 \mu \mathrm{g} / \mathrm{mL}$. Samples were injected in triplicate across its range according to the assay procedure and the data was shown in Figure - 4.

\section{LOD and LOQ}

The LOD and LOQ values were determined by the formulae LOD $=3.3$ $\sigma / \mathrm{m}$ and LOQ $=10 \sigma / \mathrm{m}$ (Where, $\sigma$ is the standard deviation of the responses and $\mathrm{m}$ is mean of the slopes of the calibration curves)

Assay

10 tablets were weighed individually and finely powdered. A powder blend equivalent to $10 \mathrm{mg}$ of FIN was transferred to a $10 \mathrm{~mL}$ volumetric flask containing about $6 \mathrm{~mL}$ of methanol, sonicated and made up to the mark with the same. The resulting solution was filtered through $0.22 \mu \mathrm{m}$ nylon membrane filter to obtain a stock solution of $1 \mathrm{mg} / \mathrm{mL}$. It was further diluted with diluent to get the required concentration $(30 \mu \mathrm{g} / \mathrm{mL})$. The solution was injected three times into the column. From the peak area obtained, the drug content in the tablets was quantified.

\section{Robustness}

Method robustness was determined by analyzing same sample at normal operating conditions and by changing, some operating analytical conditions such as flow rate and wavelength. The data was given in Table -2 .

\section{RESULTS AND DISCUSSION}

\section{Method development}

The chromatographic conditions were optimised with a view to develop a rapid and sensitive and validated RP HPLC-PDA method for analysing FIN in bulk and tablet dosage forms. Trials were carried out with Phenomenex $\mathrm{C}_{18}$ column $(150 \times 4.6 \mathrm{~mm}, 5 \mu)$ using a mobile phase of $0.02 \%$ formic acid: methanol in different ratios at a flow rate of $1 \mathrm{~mL} / \mathrm{min}$ with the detector set at $220 \mathrm{~nm}$ and separations were achieved at ambient temperature. Formic acid was chosen primarily to facilitate MS detection in the later stages of the method applicability. With 60:40 composition, FIN was not eluted with in 20 
min run time. Increasing the organic modifier to $50 \%$, FIN again was not eluted with in 20 min of runtime. Composition changed to $30: 70$ and with these conditions FIN was eluted at 8min. In another trial 20:80 composition was used where FIN was eluted at 3.4 min. A sample chromatogram of FIN under these conditions is shown in Figure - 1 along with UV spectrum and peak purity index. Peak purity index was greater than 0.9999 and indicating the absence of impurities with FIN in bulk.

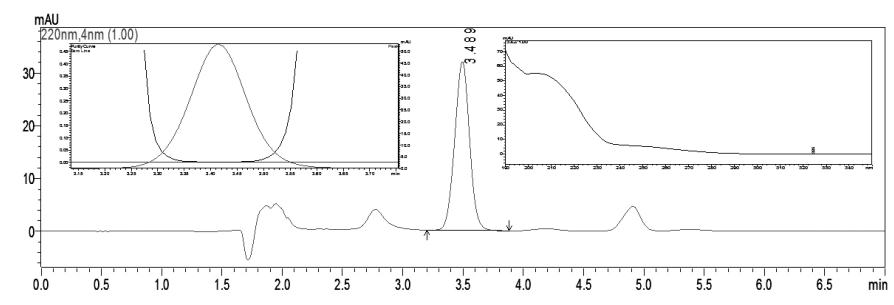

Figure1. Typical chromatogram of a standard solutions containing of $10 \mu \mathrm{g} / \mathrm{mL}$ of FIN.

\section{Method Validation}

This method described above had been validated as per the ICH guidelines [15] and the results were summarized below.

\section{Linearity and Range:}

The linearity was tested within the concentration range of $5,10,20,30$, 40 and $50 \mu \mathrm{g} / \mathrm{mL}$ of FIN. The range of concentrations was selected basing on $80-120 \%$ of the test concentration (for assay i.e. $30 \mu \mathrm{g} / \mathrm{mL}$ ). The value of the regression coefficient $\left(\mathrm{R}^{2}\right)$ was 0.998 and the correlation coefficient $(\mathrm{R})$ was 0.999 . The regression data indicated that good linearity was obtained within the concentration range tested.

\section{Precision}

Precision was measured in terms of repeatability of application and measurement.

\section{System precision:}

Repeatability of standard application was carried out using six replicates of the same standard concentration $(30 \mu \mathrm{g} / \mathrm{mL})$. The $\%$ RSD of the peak area was found to be less than $1(0.06)$ indicating an acceptable level of precision for the analytical system.

Method precision:

Repeatability of sample measurement was carried out in six replicates of the same sample preparations from same homogenous blend of marketed formulation (FINAST ${ }^{\circledR}$ tablets). The $\%$ RSD of the peak area was found to be less than $1(0.49)$

\section{Specificity}

Diluent, placebo, standard and sample solutions were analysed individually as per the method to examine interference. From the obtained data, it can be inferred that there were no co eluting or interfering peaks where FIN was eluted. This shows that the peak of analyte was pure and excipients in the formulation did not interfere with the analyte. The peak purity indices values of the standard and sample peaks were found to be greater than 0.999 and these results were in good agreement with the above results.

Accuracy

Accuracy of the method was examined by performing recovery studies by standard addition method for drug product, as the exact components are unknown. For the drug substance, the analyte peak was evaluated by $3 \mathrm{D}$ plot of the chromatogram in order to confirm the existence of one component at $3.4 \mathrm{~min}$ elution time of FIN, as the impurities were not available. From the 3 D plots it is clear that the peak eluted at 3.4 min was one component, free of impurities/excipients. The recovery of the added standard to the drug product sample was calculated and it was found to be $98.81-100.85 \%$ and the \% RSD was less than 2, which indicate a good accuracy of the method to that of the label claim.

\section{LOD and LOQ}

The limits of detection (LOD) and quantification (LOQ) were determined by the method based on the standard deviation (s) and the slope (m) of the calibration plot, using the formulae, $L O D=3.3 \mathrm{~s} / \mathrm{m}$ and $L O Q=10 \mathrm{~s} / \mathrm{m}$. The LOD and LOQ were found to be $0.311 \mu \mathrm{g} / \mathrm{mL}$ and $0.945 \mu \mathrm{g} / \mathrm{mL}$ respectively. The sensitivity was found to be enough to carry out the routine analysis of FIN in bulk and formulations

\section{Assay of the marketed formulation}

The developed method was applied to assay of FIN in the commercial tablets. The results of the assay were in good agreement with the lable amount $(100.29 \pm 0.53)$ and the error of the determination did not exceed the limit.

\section{Robustness}

Method robustness was determined by analysing the same sample at normal operating conditions and also by changing the operating analytical conditions like wavelength of detection and flow rate of the mobile phase. Percent assay values were also estimated under these changed conditions and the results were given in Table-2. Changes in the flow rate slightly affected the retention times of the FIN. However, the parameters like capacity factor, theoretical plate number and assay were not changed and were within the limits. Similar results were obtained with the changed wavelength. These results indicated that the method is robust in terms of changed flow rate and wavelength.

Table 2: Robustness data for FIN.

\begin{tabular}{|c|c|c|c|c|}
\hline $\begin{array}{c}\text { Chromatogra- } \\
\text { phic parameters }\end{array}$ & $\begin{array}{c}\text { Retention } \\
\text { time }\end{array}$ & $\begin{array}{c}\text { Capacity } \\
\text { factor }\end{array}$ & $\begin{array}{c}\text { Tailing } \\
\text { factor }\end{array}$ & \% Assay \\
\hline $\begin{array}{c}\text { Flow rate (mL/ } \\
\text { min) }\end{array}$ & & & & \\
\hline $0.95(-5 \%)$ & 3.475 & 1.126 & 0.970 & 99.91 \\
\hline 1.00 & 3.458 & 1.191 & 1.012 & 100.04 \\
\hline $1.05(+5 \%)$ & 3.455 & 1.174 & 1.009 & 100.09 \\
\hline Mean \pm SD & $3.462 \pm 0.01$ & $1.16 \pm 0.03$ & $0.997 \pm 0.02$ & $100.01 \pm 0.10$ \\
\hline Wavelength & & & & \\
\hline $219(-1)$ & 3.478 & 1.935 & 1.046 & 99.83 \\
\hline 220 & 3.478 & 1.142 & 1.045 & 99.92 \\
\hline $221(+1)$ & 3.478 & 1.154 & 1.049 & 100.02 \\
\hline Mean \pm SD & $3.47 \pm 0.00$ & $1.41 \pm 0.45$ & $1.04 \pm 0.01$ & $99.92 \pm 0.10$ \\
\hline
\end{tabular}

\section{System Suitability}

Five injections of $20 \mu \mathrm{g} / \mathrm{mL}$ standard solution were given by increasing the injection volumes from $10 \mu \mathrm{L}$ to $50 \mu \mathrm{L}$. The tailing factor was less than $2 \%$ and the theoretical plate number was well above 2000 . The $\%$ RSD obtained for all the parameters was less than $2 \%$ and all these results indicate that the present method conditions were suitable for the analysis of FIN.

Stability of the analytical solution

The stability of the standard solution was assessed by analysing at different time intervals up to 7 days stored at $4{ }^{\circ} \mathrm{C}$. The percentage variation was found to be less than $2 \%$ to the initial concentration at different time points and it was observed that the solution was stable for a period of 7 days when stored at $4^{\circ} \mathrm{C}$.

\section{CONCLUSION}

The proposed RP-HPLC - PDA method was validated fully as per International Conference on Harmonisation (ICH) Guidelines, and found to be applicable for routine quality control analysis for the estimation of FIN in isocratic mode of elution. The results of linearity, precision, accuracy and specificity, proved to be with in the limits. The method provides selective quantification of FIN without interference from blank and placebo. The proposed method is highly sensitive, reproducible, reliable, rapid and specific and also has the unique advantage of LC conditions being compatible with MS detection. Therefore, this method can be employed in quality control to estimate the amount of FIN in bulk and in dosage forms.

\section{ACKNOWLEDGEMENTS}

The authors are thankful to the Siddhartha Academy of General and Technical Education, Vijayawada, for providing the necessary facilities to carry out the research work.

\section{REFERENCES}

1. Goodman \& Gilman's The pharmacological basis of therapeutics, $9^{\text {th }}$ Edn. USA. 1996

2. The United States Pharmacopoeia/NF, The official edition compendia of standards, $29^{\text {th }}$ Ed, Asian Edition Rockville MD, 2004 
3. Indian pharmacopoeia volume -III, The Indian Pharmacopoeia commission, Ghaziabad, 2010

4. Tripathi K.P, Essentials of medical pharmacology, $6^{\text {th }}$ Edn. New Delhi, 2008

5. Maryadele J.O.N, The Merck Index , $13^{\text {th }}$ Ed , Merck Research Lab, Division of Merck \& Co. White House Station, NJ, USA, 2001

6. Martindale The Complete Drug Reference $33^{\text {rd Ed }}$, Pharmaceutical Press, The Royal Pharmaceutical Society, London, 2005

7. FQ. Guo, LF Huang, KP. Wong, YH. Dai, YW. Li J. Pharm. Biomed. Anal. 43, 1507-1513 (2007)

8. C. Xiaohong, RG. Erin KP Douglas, DF William J. Chromatog. Sci. 46 356-361 (2008)

9. P. Ptacek, J. Macek, J. Klima J. Chromatogr. 738, 305-310 (2000)
10. DD. Hulya, KU. Aysen, SA. Serap Menderes University, 4th AACD Congress, Kuşadas1-AYDIN/ TURKEY Proceedings Book, 2004

11. K. Basavaia, BC. Somashekar, Determination of Finasteride in tablets by high performance liquid chromatography, E-J. Chem. 4, 109-116 (2007).

12. J. Macek, Separation of finasteride and analogues. J Chromatogr B 764, 207-215 (2001)

13. S. Agarwal, A new spectrophotometric method for the determination of Finasteride in tablets. Chromatographia 67, 778-783 (2008).

14. ST. Ulu A new spectrophotometric method for the determination of Finasteride in tablets. Spectrochimica Acta Part A 67, 778-783 (2007)

15. Guidance for Industry - Q2B Validation of Analytical Procedures: Methodology; http://www.fda.gov/cder/guidance/index.html 